\title{
A Single Center Retrospective Analysis of Kraske’s Transsacral Approach: A Review
}

\author{
Cédric Bouts*, Kurt Van der Speeten \\ Department of Surgical Oncology, Ziekenhuis Oost-Limburg, Genk, Belgium \\ Email: ${ }^{*}$ cedric@bouts.be
}

Received 14 August 2014; revised 10 September 2014; accepted 5 October 2014

Copyright (C) 2014 by authors and Scientific Research Publishing Inc.

This work is licensed under the Creative Commons Attribution International License (CC BY). http://creativecommons.org/licenses/by/4.0/

(c) (i) Open Access

\section{Abstract}

Aim: Presacral lesions are uncommon and represent a diagnostic and surgical challenge. The aim of this study is to present our experience with Kraske's transsacral resection and to review current literature. Methods: Seven patients who had a transsacral resection between 2001 and 2013 were reviewed retrospectively. Results: Two men and five women with a mean age of 39 (range 17 60) years were diagnosed with a presacral lesion. The clinical presentation was nonspecific; pain was the most common symptom. All lesions were palpable on digital rectal examination. Magnetic resonance imaging (MRI) was necessary to assess the tumor's extent, biological behavior and relationship to adjacent structures. MRI predicted malignancy with $100 \%$ accuracy. All lesions were located below S3 and underwent a transsacral resection. Pathological examination revealed four tailgut cysts, two epidermoid cysts and one chordoma. Postoperative complications included wound infections (two cases) and spasms of the gluteus muscle (one case). We reported no recurrence or mortality. Conclusion: Clinical awareness, the use of MRI in the routine work-up and avoidance of an incisional biopsy result in a good outcome after surgical resection of presacral lesions. Kraske's approach can be used for presacral lesions below $\mathrm{S} 3$, resulting in low morbidity, no recurrence and no mortality.

\section{Keywords}

Presacral Tumor, Magnetic Resonance Imaging, Transsacral Approach, Kraske

\section{Introduction}

Presacral or retrorectal lesions are a rare and challenging surgical problem [1]-[3]. Major referral centers report an incidence of 1.4 to 6.3 adult patients per year [1] [4]. They are usually asymptomatic lesions with a comprehensive differential diagnosis on magnetic resonance imaging (MRI). Excisional biopsy is required to obtain a

\footnotetext{
*Corresponding author.
} 
pathological diagnosis [1]-[3] [5]-[7]. The presacral space is a virtual space, confined by the rectum anteriorly, sacrum and coccyx posteriorly, ureter and iliac vessels laterally, peritoneal reflection superiorly and pelvic floor muscles inferiorly. As it is the site of fusion between the embryologic hindgut and neural ectoderm, various tumors may originate from these totipotential cells [4] [8]-[10].

A landmark paper in 1885 by Paul Kraske proposed a posterior approach to the rectal and retrorectal space. It exposes the mid rectum and presacral space after partial removal of the coccyx and the sacrum [11] [12]. Since 1908, Miles's abdominoperineal approach has replaced Kraske's approach to control distal rectal cancer and its upward spread through lymphatics [13]. Kraske's approach has remained an important technique to resect presacral lesions. It provides for a good access to an anatomically difficult region. As these lesions are mostly benign and asymptomatic, minimally invasive excision is necessary [1]-[3] [6] [9] [14]-[18]. The aim of this manuscript is to present our experience with transsacral resection and to review current literature.

\section{Materials and Methods}

This study represents a single center, retrospective analysis of presacral lesions. The operative notes between 2001 and 2013 were cross-checked with the database of pathology. Following data of seven patients were obtained: patient demographics, symptoms, clinical findings, technical investigations, perioperative details, pathological diagnosis and follow-up. No patients were excluded based on these findings. All lesions were resected through Kraske's transsacral approach by the same surgeon (Figure 1). Patients were placed in the prone jackknife position. After ellipsoidal incision over the sacrococcyx and splitting of the subcutis, the sacrum was approached and pelvic floor muscles were detached. A partial transection of the sacrum at the level of S4 or S5 was needed to approach the presacral space. The presacral lesion was dissected from surrounding structures. En bloc resection was performed when adjacent structures were involved. The defect was closed in layers and a drain was left in five cases. All patients received preoperative bowel preparation and postoperative antibiotics for five days. Diagnosis was confirmed on postoperative pathological examination. Follow-up depended on histological diagnosis and postoperative problems. All patients were seen at the outpatient clinic after four weeks. Benign cases were referred to a general practitioner. One malignant case (chordoma) was seen at the outpatient

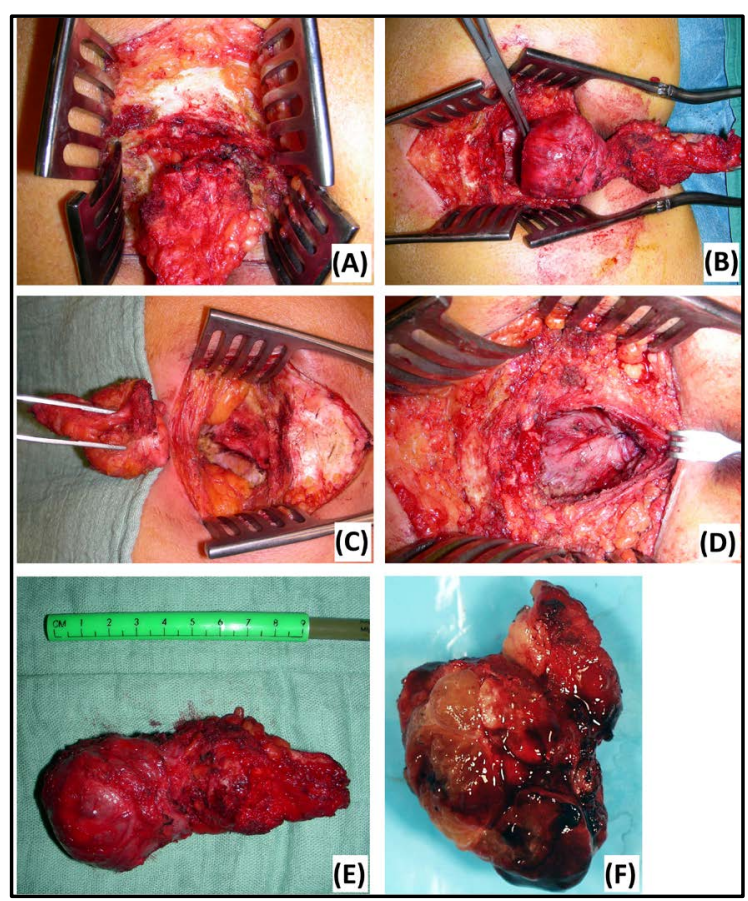

Figure 1. Kraske’s transsacral approach. (A) Partial sacrectomy at the level of S5. (D) Closure in layers. (B) En bloc resection of a tailgut cyst. (E) Tailgut cyst: macroscopic view. (C) Residual defect after resection of an epidermoid cyst. (F) Chordoma: macroscopic view. 
clinic after one, two, four, eight, eleven, eighteen and twenty-six months. This patient underwent a postoperative MRI at four, eleven and twenty-five months.

An electronic search through text items and Medline Subject Headings (MESH) terms on PubMed was conducted using following key words: presacral space, sacrococcygeal region, presacral tumor, retrorectal tumor, tailgut cyst, epidermoid cyst, chordoma, MRI, surgical treatment, transsacral approach and Kraske. The same search was repeated on LIMO, a search platform for all collections of LIBIS net-libraries. References of the obtained articles were reviewed for additional relevant papers. Case reports, systematic reviews and meta-analysis were included.

\section{Results}

Patient's demographics and clinical findings were summarized in Table 1. No patients had undergone prior pelvic surgery. Concomitant relevant history included dilated seminal vesicles with ongoing perineal pain and irritable bowel syndrome with a recurrent anal fissure. Both problems resolved after surgical resection of the presacral lesion.

Preoperative work-up was done by MRI. Findings are summarized in Table 2 and propose a broad differential diagnosis. Examples are shown in Figure 2. Two diffusion-weighted MRI's (DWI) were performed, using apparent diffusion coefficient (ADC) values at low $\left(0 \mathrm{~s} / \mathrm{mm}^{2}\right)$ and high $\left(1000 \mathrm{~s} / \mathrm{mm}^{2}\right)$ diffusion gradients. ADC values were high for both diffusion gradients (Figure 3). Five patients underwent computed tomography (CT) before MRI. Other technical investigations before MRI or CT included a positron emission tomography (PET), a transrectal ultrasonography (TRUS), a transabdominal ultrasonography and two anoscopies. No presacral lesions were found. TRUS illustrated dilated seminal vesicles. Transabdominal ultrasonography suggested acute appendicitis. One anoscopy revealed an anal fissure.

Preoperative biopsy was not indicated. Excisional resection was macroscopically complete in all cases. Rectal involvement required partial excision and closure of the rectal wall in six cases. Partial sacrectomy was performed at the level of S4 (three cases) or S5 (four cases). One defect required closure by a gluteus flap transfer and re-approximation of the external rectal sphincter. The operative time ranged from 103 to 196 minutes, with an average of 152 minutes. No intraoperative complications were noted and blood loss was negligible.

Table 1. Patients with a presacral lesion: demographics and clinical findings $(n=7)$.

\begin{tabular}{lcl}
\hline Demographics and clinical findings & Number (n) & Percentage (\%) \\
\hline Age (years) & 39 y & \\
Mean & 17 y - 60 y & \\
Range & & $71.4 \%$ \\
Gender & 5 & $28.6 \%$ \\
Female & 2 & \\
Male & & $14.3 \%$ \\
Symptoms & 1 & $85.7 \%$ \\
Asymptomatic & 6 & $28.6 \%$ \\
Symptomatic & 2 & $28.6 \%$ \\
Perineal pain & 2 & $28.6 \%$ \\
Abdominal pain & 2 & $14.3 \%$ \\
Change in bowel habit & 1 & $14.3 \%$ \\
Tenesmus & 1 & $14.3 \%$ \\
Dyspareunia & 1 & $42.9 \%$ \\
Sacral swelling & 7 & $100 \%$ \\
Digital rectal examination & 3 & \\
Palpable mass or bulge & & \\
Painful & 7 & \\
& & \\
\hline
\end{tabular}


Table 2. Presacral lesions: magnetic resonance findings $(n=7)$.

\begin{tabular}{|c|c|c|}
\hline MRI findings & Number (n) & Percentage (\%) \\
\hline \multicolumn{3}{|l|}{ Tumor location } \\
\hline Above S3 & 0 & $0 \%$ \\
\hline Below S3 & 7 & $100 \%$ \\
\hline Tumor Size (cm) & Range: 5.9 cm; Mean: 2.8 - 10.5 cm & \\
\hline Involvement of surrounding structures & 4 & $57.1 \%$ \\
\hline \multicolumn{3}{|l|}{ Tumor morphology } \\
\hline Cystic & 6 & $85.7 \%$ \\
\hline Solid & 1 & $14.3 \%$ \\
\hline \multicolumn{3}{|l|}{ Signal intensity } \\
\hline Homogeneity & 7 & $100 \%$ \\
\hline Heterogeneity & 0 & $0 \%$ \\
\hline \multicolumn{3}{|l|}{ Tumor margin } \\
\hline Sharp & 7 & $100 \%$ \\
\hline Irregular/Infiltrative & 0 & $0 \%$ \\
\hline Gadolinium enhancement & 3 & $42.9 \%$ \\
\hline \multicolumn{3}{|l|}{ Septation } \\
\hline Unilocular & 3 & $42.9 \%$ \\
\hline Polylocular & 4 & $57.1 \%$ \\
\hline \multicolumn{3}{|l|}{ Preferable diagnosis } \\
\hline Tailgut cyst & 5 & $71.4 \%$ \\
\hline Chordoma & 1 & $14.3 \%$ \\
\hline Endometriosis & 1 & $14.3 \%$ \\
\hline
\end{tabular}
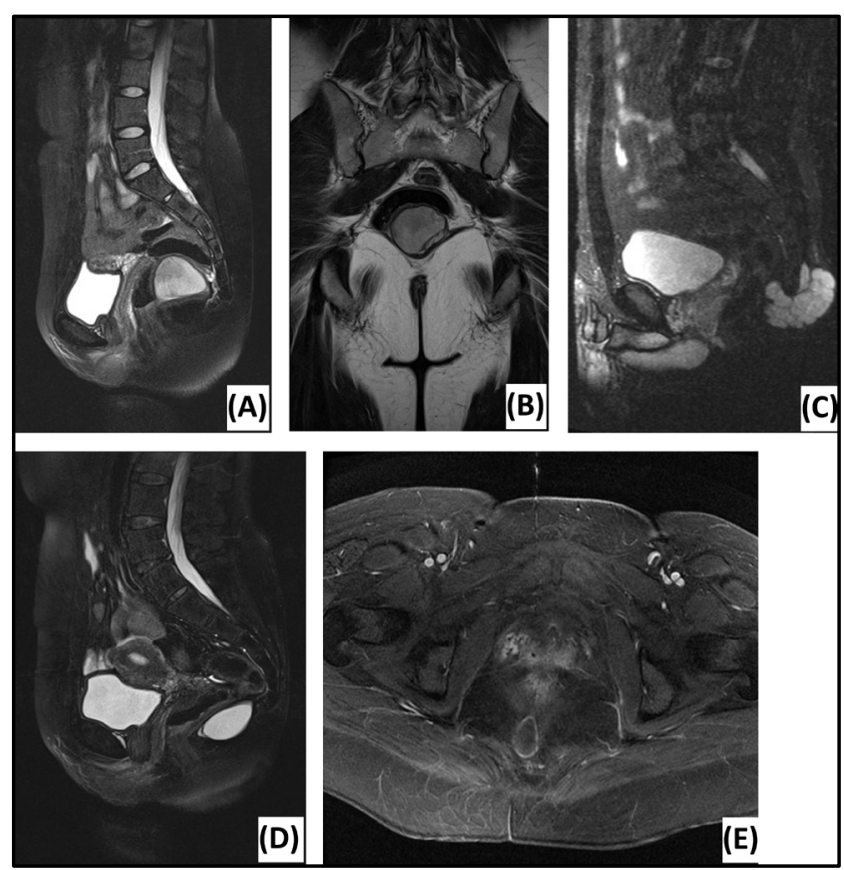

Figure 2. Magnetic resonance imaging of presacral lesions. (A) Sagittal T2-weighted MRI of a tailgut cyst: located below S3, sharp tumor margins, high signal intensity, homogeneous, unilocular. (B) Coronal T2-weighted MRI of a tailgut cyst: external compression of the rectum. (C) Sagittal T2-weighted MRI of a chordoma: located below S3, extension behind the sacrum, sharp tumor margins, high signal intensity, homogeneous, multiple septations. (D) Sagittal T2-weighted MRI of an epidermoid cyst: located below S3, sharp tumor margins, high signal intensity, homogeneous. (E) Axial T1-weighted MRI of an epidermoid cyst: Gadolinium enhancement in the wall of the lesion. 

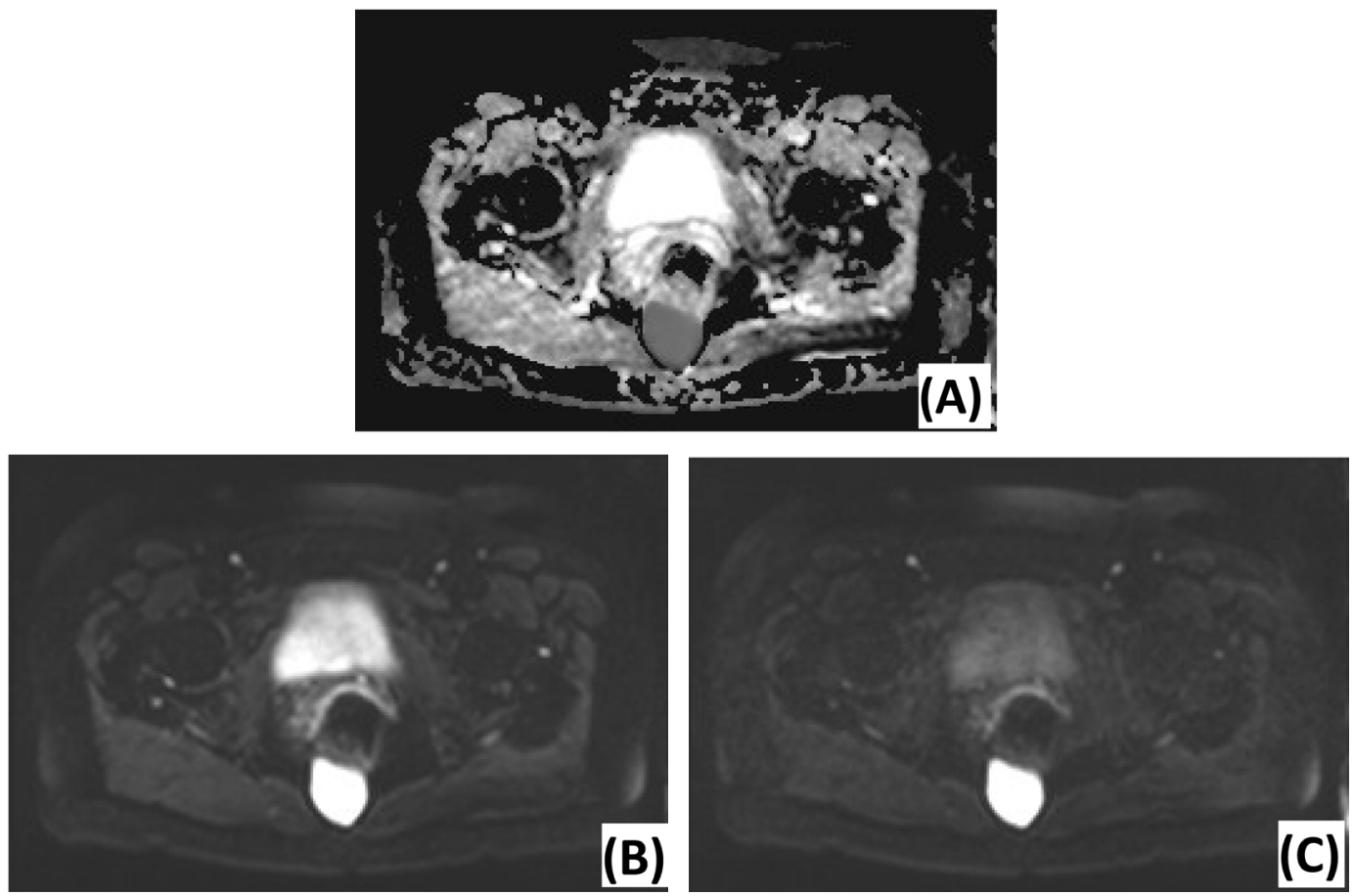

Figure 3. Diffusion-weighted MRI of an epidermoid cyst. (A) ADC map: low signal intensity. (B) DWI with low diffusion gradient $\left(b=0 \mathrm{~s} / \mathrm{mm}^{2}\right)$ : high ADC value. (C) DWI with high diffusion gradient $(b=1000$ $\mathrm{s} / \mathrm{mm}^{2}$ ): high ADC value.

The mean postoperative hospital stay was 5, 3 days, ranging from 4 to 8 days. We noted no problems, apart from perineal discomfort. All patients left the hospital in good condition. During the first month (short-term morbidity), pain and discomfort diminished. Two cases of wound infection were noted, respectively after five and thirteen days. In the initial case, a recurrent wound infection was seen after eleven days. Both cases healed after conservative wound treatment. We encountered one long-lasting complication: exercise-induced involuntary contractions of the left gluteus muscle after flap transfer. These painful episodes lasted about ten seconds. They improved progressively with physical therapy. After eighteen months, there were no problems, except when doing heavy lifting from the squat position. Final consultation after twenty-four months revealed further favorable development.

Histological diagnosis included four tailgut cysts, two epidermoid cysts and one chordoma. An overview is summarized in Table 3. Maximal diameter ranged from $2.8 \mathrm{~cm}$ to $10 \mathrm{~cm}$. Mean diameter was $5.3 \mathrm{~cm}$. Excision was microscopically complete in all cases. Tailgut cysts were characterized by their multicystic aspect, thin wall, mucoid material, various epithelial types and a surrounding disorganized muscle layer (Figure 4). Epidermoid cysts were lined with malpighian epithelium, containing laminated keratin contents. An inflammatory response, based on rupture, was present in one cyst (Figure 5). No atypia, sacral bone defects or calcifications were noted. The chordoma consisted of multiple lobules and physaliphorous cells with intracytoplasmic vacuoles (Figure 6). There were no regions of chondroid differentiation or chondrosarcoma. The cells labeled with cytokeratin and S-100 protein. The proliferation marker Ki67 was positive in less than 2\% of all cells. Sacral destruction was noted.

\section{Discussion}

Presacral lesions represent a diagnostic and surgical challenge. Presentation is asymptomatic or nonspecific. They originate from a complex anatomical region with a broad differential diagnosis and a difficult approach. [1]-[4] [6] Literature only contains small series. Jao reports the largest study, being one with 120 patients [1]. This single center retrospective analysis is in line with current literature.

\subsection{Overview of Presacral Lesions}

Presacral lesions usually occur between the age of 40 and 60 . They are classified by their predominant cell line 
Table 3. Presacral lesions: histological evaluation $(n=7)$.

\begin{tabular}{lcccc}
\hline $\begin{array}{l}\text { Histological evaluation } \\
\text { Benign }\end{array}$ & Number (n) & (Male:Female) & Percentage (\%) & (Male:Female) \\
$\begin{array}{l}\text { Tailgut cyst } \\
\text { Epidermoid cyst }\end{array}$ & 2 & $(1: 3)$ & $57.1 \%$ & $(25 \%: 75 \%)$ \\
Malignant & & $(0: 2)$ & $28.6 \%$ & $(0 \%: 100 \%)$ \\
Chordoma & 1 & $(1: 0)$ & $14.3 \%$ & $(100 \%: 0 \%)$ \\
\hline
\end{tabular}

Figure 4. Photomicrographs of a tailgut cyst. (A) HE stain illustrates the multilocular aspect, various epithelial types and a disorganized muscle layer. (B) Cytokeratin 5/6 stain illustrates the epithelial tissues. (C) Desmin stain illustrates the disorganized, interrupted muscle layer.

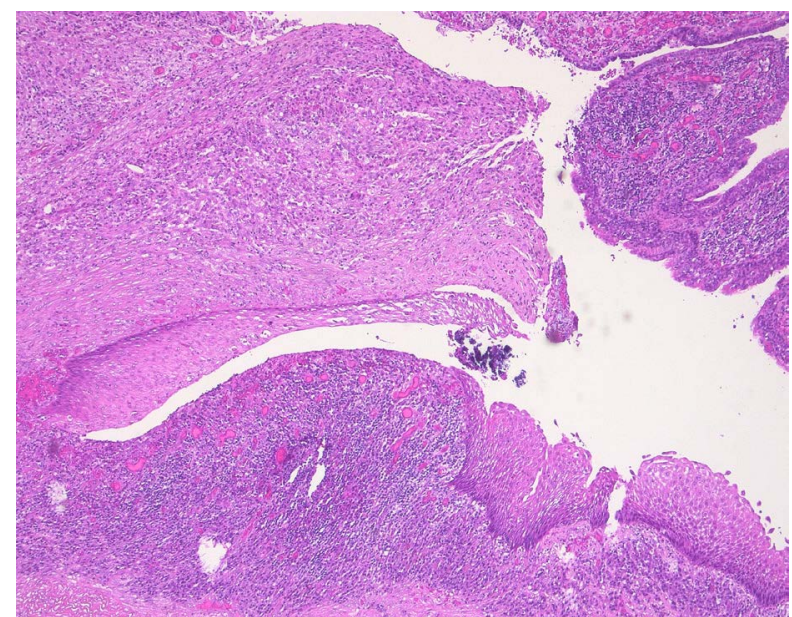

Figure 5. Photomicrograph of an epidermoid cyst. HE stain illustrates a malpighian epithelium with a granular layer. Inflammatory response due to rupture of the cyst. 

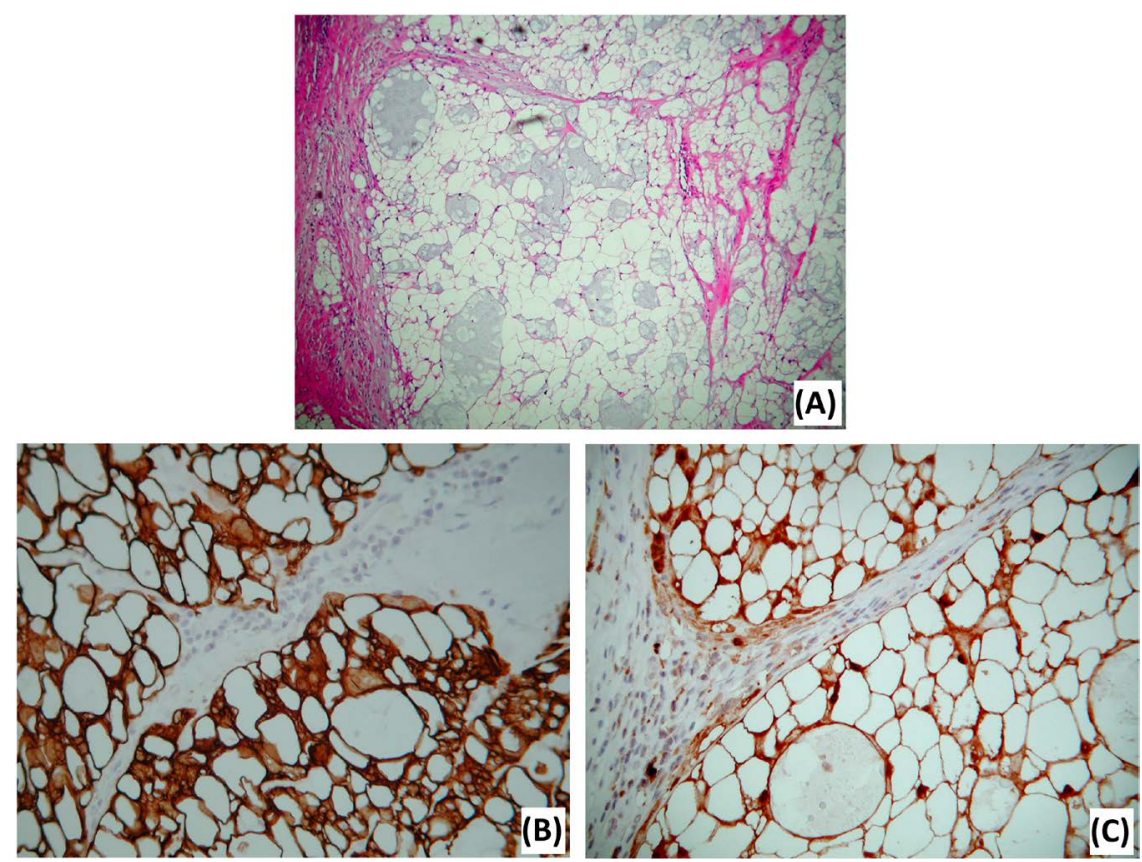

Figure 6. Photomicrographs of a chordoma. (A) HE stain illustrates the typical physaliphorous cells, containing numerous, variably sized, intracytoplasmic vacuoles. (B) Keratin stain. (C) S-100 protein stain.

type. Five categories are obtained: congenital, inflammatory, neurogenic, osseous and miscellaneous (Table 4) [4] [10] [19]. Lev-Chelouche et al. suggest another classification based on tumor origin and nature, but this has no influence on the management of an individual patient [14].

All lesions in this study were congenital. This category accounts for $55 \%$ to $70 \%$ of all presacral lesions. Developmental cysts include epidermoid cysts, dermoid cysts, tailgut cysts or teratomas, accounting for $60 \%$ of all congenital lesions [4] [8] [9] [20]. They have a male:female ratio ranging from 1:2 to 1:5, partly explained by findings during routine gynecologic investigations [2] [4] [7]. This concurs with our findings: female predominance (83.3\%) was noted in developmental cysts and one patient was referred by a gynecologist. The most common malignant presacral lesion is a chordoma. It has a male:female ratio of 2:1. Chordomas are usually slow growing lesions, rarely occur before the age of 30 and frequently cause pain and nerve impingement [4] [8] [10]. We encountered one chordoma in a 40-year-old male. He was asymptomatic, apart from sacral swelling due to tumor extension behind the sacrum. Inflammatory lesions represent abscesses, fistulas and granulomas. Some series do not include those lesions [10]. Neurogenic lesions arise from peripheral nerves, representing 10\% of all presacral lesions. Ependymomas have the highest incidence in this category. Osseous lesions represent 5\% to $10 \%$ of all presacral masses. Miscellaneous lesions are very diverse, accounting for the remaining $10 \%$ to 25\%. Metastatic disease, usually from the rectum, constitutes an important part [4] [8] [10].

\subsection{Clinical Presentation}

The asymptomatic or nonspecific presentation delays the correct diagnosis of presacral lesions. Series report 14\% to 56\% of cases without symptoms [1] [2] [9] [14]-[16] [18] [20]. We reported 85.7\% of patients having at least one symptom on detailed questioning. Misdiagnoses include fistula in ano, perianal abscesses, proctalgia fugax, pilonidal disease, psychogenic pain, back pain and postpartum pain [7] [21]. Singer et al. report seven cases which had undergone an average of 4.7 invasive procedures before being correctly diagnosed with a presacral lesion [7]. Other results conclude that $36.2 \%$ of the cases had undergone a previous procedure [16]. If symptomatic, duration between symptoms and diagnosis is an average of twelve months [1]. Possible symptoms are caused by compression, invasion, infection, necrosis or malignancy [8]-[10] [14]. Pain complaints of the perineum, back and abdomen are the most common symptoms [1] [4] [15] [16] [18] [20] [22]-[24]. Glasgow et al. conclude that male gender, an age over 60 years and pain is suggestive of malignancy. Pain complaints occur 
Table 4. Classification of presacral masses.

\begin{tabular}{|c|c|c|}
\hline Classification & Benign & Malignant \\
\hline \multirow{8}{*}{ Congenital } & Developmental cyst & Chordoma \\
\hline & Dermoid cyst & \multirow[t]{12}{*}{ Teratocarcinoma } \\
\hline & Epidermoid cyst & \\
\hline & Tailgut cyst & \\
\hline & Teratoma & \\
\hline & Anterior meningocele & \\
\hline & Rectal duplication & \\
\hline & Adrenal rest tumor & \\
\hline \multirow{5}{*}{ Inflammatory } & Granuloma & \\
\hline & Abscess & \\
\hline & perineal abscess & \\
\hline & pelvirectal abscess & \\
\hline & Fistula & \\
\hline \multirow{4}{*}{ Neurogenic } & Neurofibroma & \multirow[t]{4}{*}{ Neuro(fibro)sarcoma } \\
\hline & Neurilemmoma & \\
\hline & Ganglioneuroma & \\
\hline & Ependymoma & \\
\hline \multirow{4}{*}{ Osseous } & Osteoma & Osteosarcoma \\
\hline & Sacral bone cyst & Chondrosarcoma \\
\hline & Giant cell tumor & Ewing's sarcoma \\
\hline & & Giant cell sarcoma \\
\hline \multirow{10}{*}{ Miscellaneous } & Desmoid tumor & Metastatic disease \\
\hline & Fibroma & Fibrosarcoma \\
\hline & Leiomyoma & Leiomyosarcoma \\
\hline & Lipoma & Liposarcoma \\
\hline & Hemangioma & Hemangioendothelial sarcoma \\
\hline & Endothelioma & \multirow[t]{5}{*}{ Carcinoid } \\
\hline & Pericytoma & \\
\hline & Lymphangioma & \\
\hline & Myelolipoma & \\
\hline & Desmoid tumor & \\
\hline
\end{tabular}

in $86 \%$ to $88 \%$ of malignant lesions, in contrast to $22 \%$ to $39 \%$ of benign lesions [1] [2]. Our findings do not concur with this conclusion: pain or dyspareunia was reported in five benign lesions (83.3\%), while none were noted in the chordoma. Other common symptoms include constipation, overflow diarrhea and tenesmus, which we reported in three cases [8] [16] [18] [22] [24]. Many other, but less common symptoms are described. None were seen in this study. Sexual dysfunction, pain of lower limbs and dysfunction of lower limbs are caused by invasion of the sacral plexus. A recurrent fistula, an abscess or a secreting sinus could be a sign of an infected presacral mass [4] [7] [9] [10] [17]. Life-threatening dystocia, due to obstruction by a presacral mass, has been described in several case reports [25] [26]. A meningocele can cause postural headache and acute meningitis [27]. Anorectal stenosis is suggestive of a Currarino triad, consisting of an anorectal malformation, a sacral bony defect and a presacral mass [28].

The sensitivity of digital rectal examination is inconsistent. Several series report $75 \%$ to $100 \%$ of the presacral lesions to be palpable [1] [4] [14] [16] [17] [23]. Glasgow et al. and Bosca et al. report respectively only 35\% and $47.6 \%$ to be palpable [2]. Differences are attributed to the location and the extent of selected tumors. Lesions below S3 can be palpated on rectal examination [7] [15] [21]. This concurs with our findings. If the lesion is present on rectal examination, estimation of tumor size, location, mobility, consistency and lobulation is possible [10] [29] [30].

We conclude that clinical awareness is important to detect presacral lesions, because they are usually slow growing and latent in onset. Knowledge of possible symptoms is necessary. A digital rectal examination is rec- 
ommended, as it can detect lesions below S3. Further investigations are always indicated.

\subsection{Diagnosis}

Diagnosis of presacral lesions is based on imaging and histology: MRI has become the cornerstone in the preoperative work-up and pathological examination confirms the classification [3] [5] [10] [18].

Due to the excellent soft-tissue resolution and multiplanar capacity, MRI is the best imaging modality to assess tumor location, size, morphology and adjacent structures [5] [6] [10]. The risk of malignancy can be estimated based on following features: heterogeneity, solid appearance, irregular or infiltrative borders, variable enhancement after gadolinium administration, rapid growth and extension above S3 [3] [5] [18]. Our findings predicted malignancy with $100 \%$ accuracy, confirming the current literature. Biological behavior also correlates with diffusion restriction. DWI can distinguish benign and malignant lesions, using quantitative ADC measurements. Several authors report significantly higher ADC values at high diffusion gradients for benign lesions [31]-[33]. Our findings concur with this conclusion. Specific diagnosis by MRI is difficult. Glasgow et al. report $28 \%$ of MRI diagnoses to be in accordance with the histological diagnosis [2]. Radiological evaluation provided a differential diagnosis in order of preference. Accuracy was 57.1\%: two epidermoid cysts were mistaken for tailgut cysts and one tailgut cyst was mistaken for endometriosis. Presacral cysts usually have low signal intensity on T1-weighted images and high signal intensity on T2-weighted images. This may be influenced by the cyst's content: blood, proteins and mucins cause higher signal intensity on T1-weighted images. Fat content is best seen on T1-weighted images using fat suppression. This is suggestive of a dermoid cyst. Tailgut cysts are multicystic, in contrast to other cystic masses. A chordoma is lobulated with a heterogeneous high signal intensity on T2-weighted images and low-intermediate signal intensity on T1-weighted images. Gadolinium injection reveals a heterogeneous enhancement with a honeycomb appearance [5] [18] [34].

CT allows us to detect presacral lesions, differentiate cystic from solid lesions and evaluate tumor extent [1] [4] [9]. The soft-tissue resolution remains inferior to MRI. Glasgow et al. report 18\% of radiological diagnosis to be in accordance with histology [2]. Multi-slice CT illustrates an evolution in reconstructing and evaluating section planes [35]. CT findings always indicated the need for additional MRI to precisely define tumor characteristics.

Other technical investigations are of lesser value. Plain X-rays can reveal a mass, sacral destruction or calcifications. Calcifications are suggestive of a teratoma [4] [21]. A scimitar sign is typical for an anterior meningocele [10] [27]. X-rays are neither sensitive, nor specific and downplay possible damage [34]. Developmental cysts can be misdiagnosed as a chronic draining sinus. Fistulography can identity a presacral lesion as their origin [10]. Endoscopy can reveal an extra-luminal compression in large lesions. An edematous rectum wall is suggestive of an infected cyst [21]. Sensitivity of endoscopy has been documented at 53 percent [2]. TRUS is an inexpensive method to roughly estimate the extent of presacral lesions and their relation to the adjacent structures [6] [36]. One patient underwent TRUS to evaluate his prostate, but no presacral lesion was documented.

The role of biopsy is limited. Complications include fistula formation, abscess formation, tumor seeding, recurrence or meningitis [2] [18] [22] [30]. Transrectal biopsy is never recommended. CT-guided extrarectal or presacral biopsy is considered in inoperable cases if it changes the non-operative treatment (for example metastatic disease and lymphomas) [10] [37] [38].

Histological conformation is made postoperative and determines further follow-up. Epidermoid cysts are unilocular lesions, which are lined with stratified squamous epithelium and filled with clear fluid. They do not contain skin appendages, in contrast to dermoid cysts [8] [34]. Tailgut cysts are multicystic lesions, filled with mucoid contents and lined with ciliated columnar cells, squamous cells and transitional cells [20] [34]. Rectal duplication cysts are differentiated based on following criteria: an organized smooth-muscle coat (desmine staining), continuity with the rectum and a mucosal lining similar to the rectal mucosa [34]. Teratomas are diagnosed based on their three germ layers [9] [34]. The microscopic hallmark of chordomas are the physaliphorous cells, which contain glycogen or mucin. Conventional chordomas are characterized by the absence of mesenchymal components, in contrast to chondroidchordomas and chondrosarcomas. S-100 protein expression is typically present in both chordomas and chondrosacromas, while the latter does not express cytokeratin [39].

We conclude that MRI is the best way to evaluate the extent and characteristics of a presacral lesion. The aim is to choose the appropriate surgical approach and estimate the extent of the operation. Specific histological diagnosis is determined postoperative. 


\subsection{Treatment}

Surgical resection is required. Presacral lesions can grow and cause obstruction or invasion. Benign lesions risk causing bleeding, dystocia, infection (for example cysts or meningoceles) or malignant transformation (for example teratomas). Malignant lesions must be excised to prevent metastasis and improve life expectancy [1]-[4] [14] [16] [21].

Resection is possible through an anterior (abdominal), posterior or combined (abdominosacral) approach. This is determined by two steps:

1) Tumor extent: above or below S3.

2) Involvement of the sacrum, the pelvic sidewall and the viscera.

Woodfield et al. propose an algorithm for the surgical management of presacral tumors. A posterior approach is used for tumors below S3. Sacrectomy is necessary in case of difficult access, large tumors or sacral involvement. Tumors above S3 or tumors with involvement of the pelvic sidewall or the viscera require an anterior approach. A combined approach is recommended in the following cases: tumor extension above and below S3, sacral invasion in lesions above S3 and involvement of the sacrum with the pelvic sidewall or the viscera in lesions below S3 [3]. Other series report similar conclusions, but the proximal border differs between S2, S3 and S4 [2] [4] [10] [18] [23] [24] [30].

Several posterior approaches are described: perineal, transsacral, transanal, intersphincteric, transsphincteric and transvaginal. Table 5 provides an overview of their uses and limitations [3] [6] [9] [10] [17] [20] [40]-[42].

The transsacral approach represents a minimally invasive way to provide an excellent view of low-lying presacral tumors and sacral nerve roots. Kraske's approach lost support because of high rates of morbidity (70\%) and recurrence (90\%) of distal rectal cancer [43]. Local posterior excision of early rectal cancer still has a place in selected patients, but a transanal approach is preferred [44] [45]. Kraske's approach is successfully used for presacral lesions resulting in low morbidity, recurrence and mortality [3] [16] [21] [40]. Complications include

\section{Table 5. Different posterior approaches: uses and limitations.}

\begin{tabular}{|c|c|c|}
\hline Posterior approaches & Uses and advantages & Limitations and disadvantages \\
\hline \multirow{4}{*}{ Perineal } & Good exposition of distal presacral space & \multirow{4}{*}{$\begin{array}{l}\text { Only for low-lying lesions } \\
\text { Limited visualization of possible cranial extension }\end{array}$} \\
\hline & $\begin{array}{l}\text { For lesions deeper and higher compared to an } \\
\text { intersphincteric approach }\end{array}$ & \\
\hline & Preservation of coccyx with less postoperative pain & \\
\hline & Preservation of sphincter function & \\
\hline \multirow{5}{*}{ Transsacral } & Best exposition of the presacral space & \multirow{5}{*}{$\begin{array}{l}\text { No visualization of pelvic vessels: risk of bleeding } \\
\text { Risk of posterior discomfort } \\
\text { Risk of wound dehiscence } \\
\text { Risk of fistula formation } \\
\text { Risk of sacral nerve injury }\end{array}$} \\
\hline & For lesions higher compared a perineal approach & \\
\hline & Less recurrence compared to a perineal approach & \\
\hline & Preservation of sphincter function & \\
\hline & $\begin{array}{l}\text { Resection of mid-rectal lesions in carefully selected } \\
\text { patients }\end{array}$ & \\
\hline \multirow{3}{*}{ Transsphincteric } & Good exposition of the mid rectal lumen & Only for low-lying lesions \\
\hline & Useful in case of extension into the rectal wall & Risk of sphincter dysfunction \\
\hline & Avoidance of sacral nerve injury & Risk of fecal fistula formation \\
\hline \multirow[b]{2}{*}{ Intersphincteric } & \multirow{2}{*}{$\begin{array}{l}\text { Avoidance of sacral nerve injury } \\
\text { Preservation of sphincter function }\end{array}$} & Only for very low-lying lesions \\
\hline & & $\begin{array}{l}\text { Contra-indication in case of preoperative suspicion of } \\
\text { malignancy }\end{array}$ \\
\hline \multirow{6}{*}{ Transanal/rectal } & & Limited visualization of presacral space \\
\hline & Useful in case of transrectal ruptured cysts & Risk of incomplete resection (cystic lesions) \\
\hline & Useful for rectal polyps & Risk of bleeding \\
\hline & \multirow{3}{*}{$\begin{array}{l}\text { First choice in local treatment of early rectal cancer } \\
\text { for carefully selected patients }\end{array}$} & Risk of fecal incontinence \\
\hline & & Special material \\
\hline & & Technical experience \\
\hline \multirow{3}{*}{ Transvaginal } & \multirow{3}{*}{ Useful in cases that deviate from the midline } & Only for prerectal lesions \\
\hline & & Risk of rectovaginal fistula formation \\
\hline & & Risk of dyspareunia \\
\hline
\end{tabular}


intraoperative bleeding, fistula development, wound infection, rectal injury, incontinency, impotency and recurrence [1] [2] [15] [18] [23] [24] [40]. Blood loss is minimal with little need for transfusion [2] [16]. There was no transfusion required in our series. Intraoperative bleeding can be dangerous, as this approach does not allow for good visualization of the vasculature [6] [15] [23]. Pelvic packing may be necessary to stop the hemorrhage [15] [18]. Partial sacrectomy and intraoperative cystic drainage allow for better oversight, although cystic drainage increases the risk of seeding [15]. An extraperitoneal iliac incision for vascular isolation can be useful in large tumors [6]. Fistula formation is a common complication [40] [43] [46]. Recent series report less fistula formation (0\% - 20\%) if Kraske's approach is strictly used for presacral instead of rectal lesions [1] [3] [16]-[18] [22] [24]. Rectal damage increases the risk of postoperative fistulas. We reported no fistulas, although partial excision of the rectal wall was needed in six cases. Inserting a finger in the rectum helped to differentiate rectal fibers from surrounding tissues and also prevented rectal injury. Preoperative bowel preparation is indispensable. Recent studies report an incidence of wound infections between 4.3\% and 30\% [1] [14]-[16] [18] [22] [24]. This is consistent with our findings (28.5\%). Postoperative antibiotic prophylaxis remains important. One infection occurred after resecting a large mass $(>10 \mathrm{~cm})$. Flap transfer can provide a solution by preventing traction and improve healing in large defects. It is also useful in preventing wound dehiscence after partial sacrectomy [2]. We encountered involuntary contractions of the gluteus muscle after a gluteus flap transfer. There were two possible explanations: resection of the sacrum caused partial removal of the anchoring of the gluteus musculature or placement of a transgluteal drain damaged a motoric nerve. The contractions improved with physiotherapy. In our series, resections were limited to the level of S4. Incontinence and impotency are complications due to nerve damage: a unilateral S3 root must be preserved [2] [9] [10].

Prognosis depends on the pathology and surgical margins [4] [10]. Benign lesions are more likely to be resected completely compared to malignant lesions [14] [15]. Little manipulation and no laceration of the tumor are important factors in preventing recurrence [14]. Partial sacrectomy is associated with less recurrence compared to a perineal approach, especially for cystic lesions and teratomas [9] [20]. En bloc resection is important when surrounding structures are involved [3]. Lev-Chelouche et al. report different recurrence and survival rates for benign, malignant, congenital and acquired lesions [14]. We report no significant morbidity, recurrence or mortality, bearing in mind the large proportion of benign lesions (85.7\%). Benign lesions have a survival rate of approximately $100 \%$ with a low recurrence rate [4] [10] [17]. Jao et al. report $15.2 \%$ recurrence of benign lesions [1]. Malignant lesions have a worse prognosis. Jao et al. report an overall five-year survival rate of $17 \%$, although chordomas have a better prognosis (five-year survival rate of 75\%) [1]. Glasgow et al. report a 100\% recurrence rate with a median disease-free time span of 24 months [2]. Woodfield et al. report recurrence in two of seven malignant lesions, both chordomas [3]. Reports of a longer recurrence-free interval after aggressive postoperative radiation therapy remain anecdotal [2]. We report no recurrence or mortality ten years after radical resection of a chordoma.

\section{Conclusion}

Presacral lesions are rare. Diagnosis is difficult given the various presentations. MRI provides an excellent way to evaluate presacral lesions, assess the risk of malignancy and determine the surgical approach. Kraske's transsacral approach is the first choice for presacral lesions below S3, if the pelvic sidewall or viscera are not involved. It results in a good outcome, low morbidity, no recurrence and no mortality. Kraske's approach belongs to a surgeon's armamentarium.

\section{Acknowledgements}

The authors thank Dr. Geert Verswijvel and Dr. Johan Van Robays for their expertise concerning the radiological and histological images.

\section{Disclosure Statement}

Theauthors declare that they have no competing interests.

\section{References}

[1] Jao, S.W., Beart Jr., R.W., Spencer, R.J., Reiman, H.M. and Ilstrup, D.M. (1985) Retrorectal Tumors. Mayo Clinic 
Experience, 1960-1979. Diseases of the Colon \& Rectum, 28, 644-652. http://dx.doi.org/10.1007/BF02553440

[2] Glasgow, S.C., Birnbaum, E.H., Lowney, J.K., Fleshman, J.W., Kodner, I.J., Mutch, D.G., et al. (2005) Retrorectal Tumors: A Diagnostic and Therapeutic Challenge. Diseases of the Colon \& Rectum, 48, 1581-1587. http://dx.doi.org/10.1007/s10350-005-0048-2

[3] Woodfield, J.C., Chalmers, A.G., Phillips, N. and Sagar, P.M. (2008) Algorithms for the Surgical Management of Retrorectal Tumours. British Journal of Surgery, 95, 214-221. http://dx.doi.org/10.1002/bjs.5931

[4] Hobson, K.G., Ghaemmaghami, V., Roe, J.P., Goodnight, J.E. and Khatri, V.P. (2005) Tumors of the Retrorectal Space. Diseases of the Colon \& Rectum, 48, 1964-1974. http://dx.doi.org/10.1007/s10350-005-0122-9

[5] Yang, B.L., Gu, Y.F., Shao, W.J., Chen, H.J., Sun, G.D., Jin, H.Y., et al. (2010) Retrorectal Tumors in Adults: Magnetic Resonance Imaging Findings. World Journal of Gastroenterology, 16, 5822-5829. http://dx.doi.org/10.3748/wjg.v16.i46.5822

[6] Wolpert, A., Beer-Gabel, M., Lifschitz, O. and Zbar, A.P. (2002) The Management of Presacral Masses in the Adult. Techniques in Coloproctology, 6, 43-49. http://dx.doi.org/10.1007/s101510200008

[7] Singer, M.A., Cintron, J.R., Martz, J.E., Schoetz, D.J. and Abcarian, H. (2003) Retrorectal Cyst: A Rare Tumor Frequently Misdiagnosed. Journal of the American College of Surgeons, 196, 880-886. http://dx.doi.org/10.1016/S1072-7515(03)00133-9

[8] Bullard Dunn, K. (2010) Retrorectal Tumors. Surgical Clinics of North America, 90, 163-171, Table of Contents. http://dx.doi.org/10.1016/j.suc.2009.09.009

[9] Ghosh, J., Eglinton, T., Frizelle, F.A. and Watson, A.J. (2007) Presacral Tumours in Adults. Surgeon, 5, 31-38. http://dx.doi.org/10.1016/S1479-666X(07)80109-0

[10] Hassan, I. and Wietfeldt, E.D. (2009) Presacral Tumors: Diagnosis and Management. Clinics in Colon and Rectal Surgery, 22, 84-93. http://dx.doi.org/10.1055/s-0029-1223839

[11] Kraske, P. (1885) Zur Exstirpation Hochsitzender Mast Darm Krebse. Verhandlungen der Deutschen Gesellschaft für Chirurgie, 14, 464-474.

[12] Kraske, P., Perry, E.G. and Hinrichs, B. (1989) A New Translation of Professor Dr P. Kraske’s Zur Exstirpation Hochsitzender Mastdarmkrebse. 1885. Australian and New Zealand Journal of Surgery, 59, 421-424.

[13] Campos, F.G., Habr-Gama, A., Nahas, S.C. and Perez, R.O. (2012) Abdominoperineal Excision: Evolution of a Centenary Operation. Diseases of the Colon Rectum, 55, 844-853. http://dx.doi.org/10.1097/DCR.0b013e31825ab0f7

[14] Lev-Chelouche, D., Gutman, M., Goldman, G., Even-Sapir, E., Meller, I., Issakov, J., et al. (2003) Presacral Tumors: A Practical Classification and Treatment of a Unique and Heterogeneous Group of Diseases. Surgery, 133, 473-478. http://dx.doi.org/10.1067/msy.2003.118

[15] Lin, C., Jin, K., Lan, H., Teng, L., Lin, J. and Chen, W. (2011) Surgical Management of Retrorectal Tumors: A Retrospective Study of a 9-Year Experience in a Single Institution. Journal of OncoTargets and Therapy, 4, 203-208.

[16] Chereau, N., Lefevre, J.H., Meurette, G., Mourra, N., Shields, C., Parc, Y., et al. (2013) Surgical Resection of Retrorectal Tumours in Adults: Long-Term Results in 47 Patients. Colorectal Disease, 15, e476-e482. http://dx.doi.org/10.1111/codi.12255

[17] Buchs, N., Taylor, S. and Roche, B. (2007) The Posterior Approach for Low Retrorectal Tumors in Adults. International Journal of Colorectal Disease, 22, 381-385. http://dx.doi.org/10.1007/s00384-006-0183-9

[18] Macafee, D.A., Sagar, P.M., El-Khoury, T. and Hyland, R. (2012) Retrorectal Tumours: Optimization of Surgical Approach and Outcome. Colorectal Disease, 14, 1411-1417. http://dx.doi.org/10.1111/j.1463-1318.2012.02994.X

[19] Uhlig, B.E. and Johnson, R.L. (1975) Presacral Tumors and Cysts in Adults. Diseases of the Colon Rectum, 18, 581589. http://dx.doi.org/10.1007/BF02587141

[20] Hjermstad, B.M. and Helwig, E.B. (1988) Tailgut Cysts. Report of 53 Cases. American Journal of Clinical Pathology, 89, 139-147.

[21] Ludwig, K. and Kalady, M. (2005) Trans-Sacral Approaches for Presacral Cyst/Rectal Tumor. Operative Techniques in General Surgery, 7, 126-136. http://dx.doi.org/10.1053/j.optechgensurg.2005.08.005

[22] Kye, B.H., Kim, H.J., Cho, H.M., Chin, H.M. and Kim, J.G. (2011) Clinicopathological Features of Retrorectal Tumors in Adults: 9 Years of Experience in a Single Institution. Journal of the Korean Surgical Society, 81, 122-127. http://dx.doi.org/10.4174/jkss.2011.81.2.122

[23] Li, G.D., Chen, K., Fu, D., Ma, X.J., Sun, M.X., Sun, W., et al. (2011) Surgical Strategy for Presacral Tumors: Analysis of 33 Cases. Chinese Medical Journal (English Edition), 124, 4086-4091.

[24] Bosca, A., Pous, S., Artes, M.J., Gomez, F., Castro, P.G. and Garcia-Granero, E. (2012) Tumours of the Retrorectal Space: Management and Outcome of a Heterogeneous Group of Diseases. Colorectal Disease, 14, 1418-1423. http://dx.doi.org/10.1111/j.1463-1318.2012.03016.x 
[25] Grahovac, G., Vilendecic, M., Vukelic-Markovic, M., Topic, I. and Lambasa, S. (2011) An Unexpected Obstacle: A Retrorectal Mass Went Undetected until the Patient Was in Labor. American Journal of Obstretics and Gynecology, 205, 578.

[26] Foruhan, B. and Jennings, P.J. (1978) Unusual Presacral Tumours Obstructing Delivery. British Journal of Obstetrics and Gynaecology, 85, 231-233. http://dx.doi.org/10.1111/j.1471-0528.1978.tb10488.x

[27] Oren, M., Lorber, B., Lee, S.H., Truex Jr., R.C. and Gennaro, A.R. (1977) Anterior Sacral Meningocele: Report of Five Cases and Review of the Literature. Diseases of the Colon Rectum, 20, 492-505. http://dx.doi.org/10.1007/BF02586588

[28] Lee, S.C., Chun, Y.S., Jung, S.E., Park, K.W. and Kim, W.K. (1997) Currarino Triad: Anorectal Malformation, Sacral Bony Abnormality and Presacral Mass-A Review of 11 Cases. Journal of Pediatric Surgery, 32, 58-61. http://dx.doi.org/10.1016/S0022-3468(97)90094-4

[29] Ludwig, K. and Kalady, M. (2005) Trans-Sacral Approaches for Presacral Cyst/Rectal Tumor. Operative Techniques in General Surgery, 7, 126-136. http://dx.doi.org/10.1053/j.optechgensurg.2005.08.005

[30] Aranda-Narvaez, J.M., Gonzalez-Sanchez, A.J., Montiel-Casado, C., Sanchez-Perez, B., Jimenez-Mazure, C., ValleCarbajo, M., et al. (2012) Posterior Approach (Kraske Procedure) for Surgical Treatment of Presacral Tumors. World Journal of Gastrointestinal Surgery, 4, 126-130. http://dx.doi.org/10.4240/wjgs.v4.i5.126

[31] Demir, O.I., Obuz, F., Sagol, O. and Dicle, O. (2007) Contribution of Diffusion-Weighted MRI to the Differential Diagnosis of Hepatic Masses. Diagnostic and Interventional Radiology, 13, 81-86.

[32] Avcu, S., Koseoglu, M.N., Ceylan, K., Bulut, M.D. and Unal, O. (2011) The Value of Diffusion-Weighted MRI in the Diagnosis of Malignant and Benign Urinary Bladder Lesions. The British Journal of Radiology, 84, 875-882. http://dx.doi.org/10.1259/bjr/30591350

[33] Esen, M., Onur, M.R., Akpolat, N., Orhan, I. and Kocakoc, E. (2013) Utility of ADC Measurement on DiffusionWeighted MRI in Differentiation of Prostate Cancer, Normal Prostate and Prostatitis. Quantitative Imaging in Medicine and Surgery, 3, 210-216.

[34] Dahan, H., Arrive, L., Wendum, D., le Pointe, H.D., Djouhri, H. and Tubiana, J.M. (2001) Retrorectal Developmental Cysts in Adults: Clinical and Radiologic-Histopathologic Review, Differential Diagnosis and Treatment. Radiographics, 21, 575-584. http://dx.doi.org/10.1148/radiographics.21.3.g01ma13575

[35] Pappalardo, G., Frattaroli, F.M., Casciani, E., Moles, N., Mascagni, D., Spoletini, D., et al. (2009) Retrorectal Tumors: The Choice of Surgical Approach Based on a New Classification. The American Surgeon, 75, 240-248.

[36] Rifkin, M.D. and Marks, G.J. (1985) Transrectal US as an Adjunct in the Diagnosis of Rectal and Extrarectal Tumors. Radiology, 157, 499-502. http://dx.doi.org/10.1148/radiology.157.2.3901110

[37] Gupta, S., Nguyen, H.L., Morello Jr., F.A., Ahrar, K., Wallace, M.J., Madoff, D.C., et al. (2004) Various Approaches for CT-Guided Percutaneous Biopsy of Deep Pelvic Lesions: Anatomic and Technical Considerations. Radiographics, 24, 175-189. http://dx.doi.org/10.1148/rg.241035063

[38] Verazin, G., Rosen, L., Khubchandani, I.T., Sheets, J.A., Stasik, J.J. and Riether, R. (1986) Retrorectal Tumor: Is Biopsy Risky? Southern Medical Journal, 79, 1437-1439. http://dx.doi.org/10.1097/00007611-198611000-00028

[39] Sell, M., Sampaolo, S., Di Lorio, G. and Theallier, A. (2004) Chordomas: A Histological and Immunohistochemical Study of Cases with and without Recurrent Tumors. Clinical Neuropathology, 23, 277-285.

[40] Lorentziadis, M. and Poulantzas, I. (2010) Kraske’s Posterior Approach to the Mid Rectum: Does It Still Have a Place in the Surgeon's Armentarium? Annals of Gastroenterology, 23, 302-306.

[41] Localio, S.A., Eng, K. and Ranson, J.H. (1980) Abdominosacral Approach for Retrorectal Tumors. Annals of Surgery, 191, 555-560. http://dx.doi.org/10.1097/00000658-198005000-00006

[42] Harvey, E.H., Young, M.R., Flanigan, T.L., Carlin, A.M., White, M.T., Tyburski, J.G., et al. (2004) Complications Are Increased with the Need for an Abdominal-Assisted Kraske Procedure. The American Surgeon, 70, 193-196.

[43] Onaitis, M., Ludwig, K., Perez-Tamayo, A., Gottfried, M., Russell, L., Shadduck, P., et al. (2006) The Kraske Procedure: A Critical Analysis of a Surgical Approach for Mid-Rectal Lesions. Journal of Surgical Oncology, 94, $194-202$. http://dx.doi.org/10.1002/jso.20591

[44] Sharma, A., Hartley, J. and Monson, J.R. (2003) Local Excision of Rectal Tumors. Surgical Oncology, 12, 51-61. http://dx.doi.org/10.1016/S0960-7404(03)00007-0

[45] Visser, B.C., Varma, M.G. and Welton, M.L. (2001) Local Therapy for Rectal Cancer. Surgical Oncology, 10, 61-69. http://dx.doi.org/10.1016/S0960-7404(01)00021-4

[46] Wilson, S.E. and Gordon, H.E. (1969) Excision of Rectal Lesions by the Kraske Approach. The American Journal of Surgery, 118, 213-217. http://dx.doi.org/10.1016/0002-9610(69)90123-8 
Scientific Research Publishing (SCIRP) is one of the largest Open Access journal publishers. It is currently publishing more than 200 open access, online, peer-reviewed journals covering a wide range of academic disciplines. SCIRP serves the worldwide academic communities and contributes to the progress and application of science with its publication.

Other selected journals from SCIRP are listed as below. Submit your manuscript to us via either submit@scirp.org or Online Submission Portal.
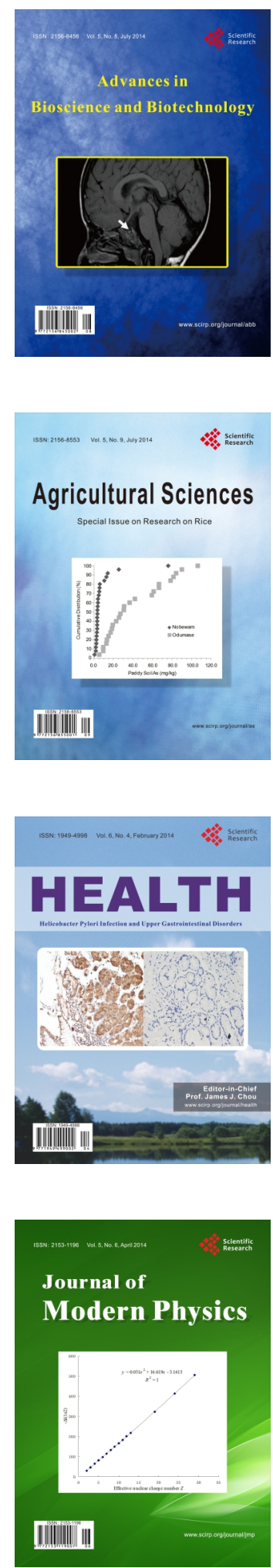
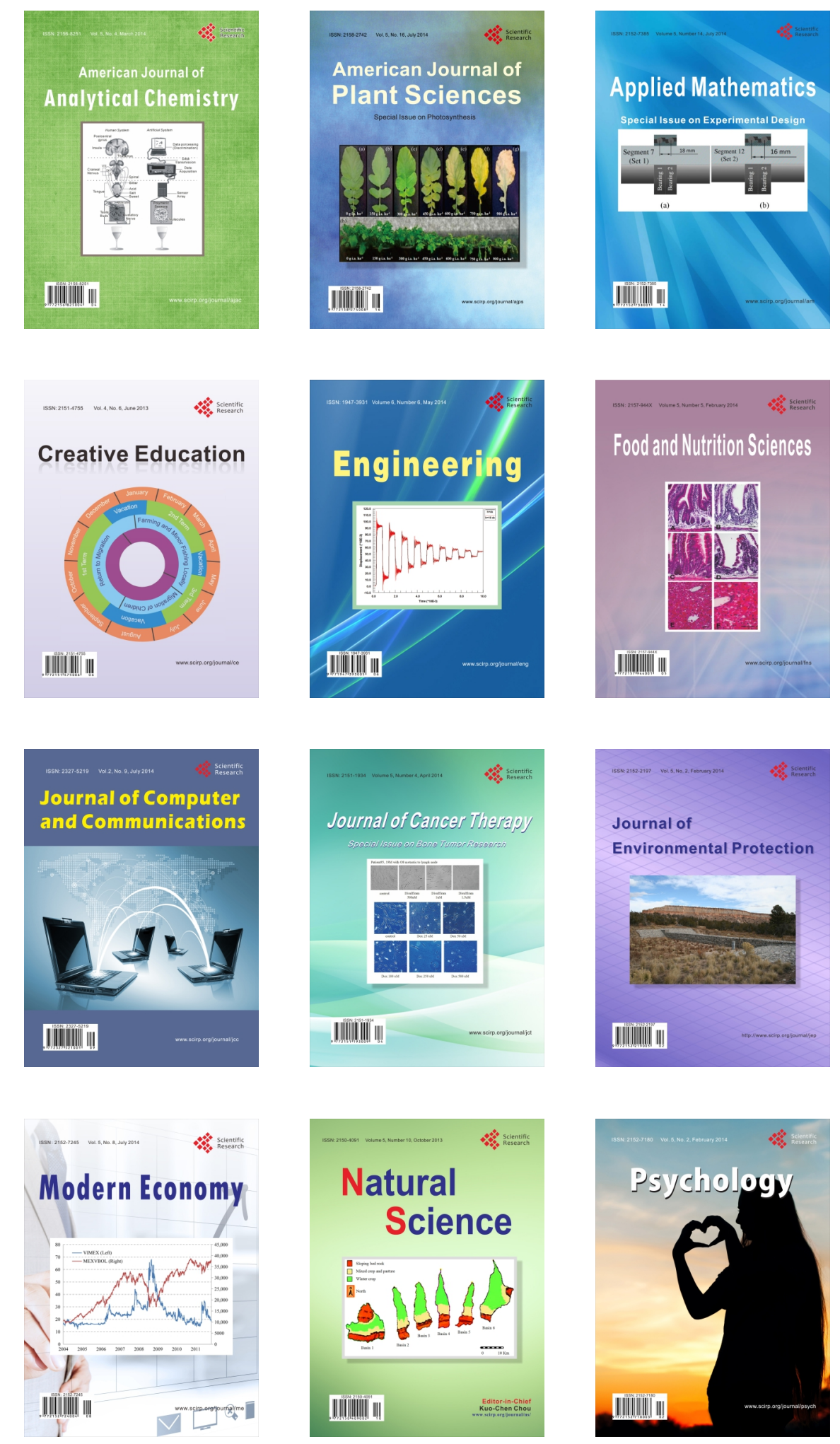